\title{
Thymidine phosphorylase induction by ionizing radiation antagonizes 5-fluorouracil resistance in human ductal pancreatic adenocarcinoma
}

\author{
Lucas D. Lee ${ }^{1}$ - Ioannis Pozios ${ }^{1}$. Verena Liu ${ }^{1}$ - Silke B. Nachbichler ${ }^{2}$. Dirk Böhmer ${ }^{3}$. Carsten Kamphues ${ }^{1}$. \\ Katharina Beyer ${ }^{1} \cdot$ Christiane J. Bruns $^{4} \cdot$ Martin E. Kreis ${ }^{1} \cdot$ Hendrik Seeliger $^{1,5}$ (i)
}

Received: 12 March 2021 / Accepted: 9 January 2022 / Published online: 27 January 2022

(C) The Author(s) 2022

\begin{abstract}
Chemoresistance in pancreatic ductal adenocarcinoma (PDAC) frequently contributes to failure of systemic therapy. While the radiosensitizing properties of 5-fluorouracil (FU) are well known, it is unknown whether ionizing radiation (IR) sensitizes towards FU cytotoxicity. Here, we hypothesize that upregulation of thymidine phosphorylase (TP) by IR reverses FU chemoresistance in PDAC cells. The FU resistant variant of the human PDAC cell line AsPC-1 (FU-R) was used to determine the sensitizing effects of IR. Proliferation rates of FU sensitive parental (FU-S) and FU-R cells were determined by WST-1 assays after low $(0.05 \mathrm{~Gy})$ and intermediate dose ( $2.0 \mathrm{~Gy})$ IR followed by FU treatment. TP protein expression in PDAC cells before and after IR was assessed by Western blot. To analyze the specificity of the FU sensitizing effect, TP was ablated by siRNA. FU-R cells showed a 2.7 -fold increase of the half maximal inhibitory concentration, compared to FU-S parental cells. Further, FU-R cells showed a concomitant IR resistance towards both doses applied. When challenging both cell lines with FU after IR, FU-R cells had lower proliferation rates than FU-S cells, suggesting a reversal of chemoresistance by IR. This FU sensitizing effect was abolished when TP was blocked by anti-TP siRNA before IR. An increase of TP protein expression was seen after both IR doses. Our results suggest a TP dependent reversal of FU-chemoresistance in PDAC cells that is triggered by IR. Thus, induction of TP expression by low dose IR may be a therapeutic approach to potentially overcome FU chemoresistance in PDAC.
\end{abstract}

Keywords Pancreatic cancer $\cdot 5$-fluorouracil $\cdot$ Thymidine phosphorylase $\cdot$ Irradiation $\cdot$ Chemotherapy resistance

\begin{tabular}{|c|c|}
\hline \multicolumn{2}{|c|}{ Abbreviations } \\
\hline DPD & Dihydropyrimidine dehydrogenase \\
\hline dRib & 2-deoxy-D-ribose \\
\hline
\end{tabular}

Lucas D. Lee and Ioannis Pozios equally contributed.

Hendrik Seeliger

hendrik.seeliger@iu.org

1 Department of General and Visceral Surgery, CharitéUniversitätsmedizin Berlin, Corporate Member of Freie Universität Berlin and Humboldt-Universität zu Berlin, 12200 Berlin, Germany

2 Department of Radiotherapy and Radiation Oncology, Klinikum der Universität München, 81377 Munich, Germany

3 Department of Radiation Oncology and Radiotherapy, Charité-Universitätsmedizin Berlin, Corporate Member of Freie Universität Berlin and Humboldt-Universität zu Berlin, 12200 Berlin, Germany

4 Department of Surgery, University Hospital of Cologne, 50937 Cologne, Germany

5 IU Health University, 10243 Berlin, Germany

$\begin{array}{ll}\text { FdU } & \text { 5-fluoro-deoxyuridine } \\ \text { FdUMP } & \text { 5-deoxyuridine monophosphate } \\ \text { FU } & \text { 5-fluorouracil } \\ \text { IFN } \gamma & \text { Interferon gamma } \\ \text { IR } & \text { Ionizing radiation } \\ \text { PDAC } & \text { Pancreatic ductal adenocarcinoma } \\ \text { TK } & \text { Thymidine kinase } \\ \text { TP } & \text { Thymidine phosphorylase } \\ \text { TS } & \text { Thymidylate synthetase }\end{array}$

\section{Introduction}

Pancreatic ductal adenocarcinoma (PDAC) is the fourth leading cause of cancer-related deaths in western countries (Siegel et al. 2020). Up to 20 percent of PDAC patients present with resectable disease, yet their prognosis remains poor (van Roessel et al. 2020). Overall survival is widely known to be worse in non-curative PDAC patients despite treatment with modern chemo- and immunotherapeutic 
agents (Conroy et al. 2018). Resistance towards cytotoxic agents, ionizing radiation (IR), or both, confers biological aggressiveness and accounts for poor therapeutic response.

5-fluorouracil (FU) is the backbone of systemic therapy of PDAC in palliative and adjuvant settings (Conroy et al. 2011; Conroy et al. 2018). As a pyrimidine analog, FU exerts its anticancer effects by incorporating its metabolites into DNA and inhibition of thymidylate synthase (TS), a key enzyme of DNA biosynthesis (Longley et al. 2003). Innate or acquired resistance of cancer cells diminishes the effectiveness of most chemotherapeutic agents. To overcome therapeutic resistance towards FU, the mechanisms of FU activation and development of resistance need to be addressed.

Thymidine phosphorylase (TP) is a key enzyme of the FU metabolism and plays a dual role in cancer development and therapy. On the one hand, TP promotes tumor growth and progression by preventing apoptosis and inducing angiogenesis via converting thymidine into its metabolite 2-deoxy-D-ribose (dRib), which has angiogenic properties (Bronckaers et al. 2009; Dikici et al. 2019; Seeliger et al. 2004). On the other hand, TP is necessary for the conversion of FU into its biologically active metabolite 5-deoxyuridine monophosphate (FdUMP) (Schuller et al. 2000), so TP induction combined with these chemotherapeutic agents is beneficial (Bronckaers et al. 2009; Toi et al. 2004). TP is highly expressed in solid tumors including PDAC (Lindskog et al. 2014) and is upregulated by chemotherapeutic agents as well as by IR (Hasegawa et al. 2012).

Low dose IR alters the expression of multiple genes and protects non-tumor cells from injury by subsequent higher irradiation doses through the activation of cell protective signaling pathways (Hou et al. 2015). At the same time, low dose IR has been shown to affect tumor cell proliferation in PDAC and other solid tumors (Liu et al. 2019; Schwarz et al. 2008). Here, we hypothesize that low dose IR induces an upregulation of TP that may antagonize the therapeutic resistance of PDAC cells towards FU.

\section{Materials and methods}

\section{Cell culture and reagents}

The FU-sensitive (FU-S) human PDAC cell line AsPC-1 (ATCC, Rockwell, MD, USA) was maintained in culture as adherent monolayer in Dulbecco's minimal essential medium (Invitrogen, Karlsruhe, Germany), supplemented with $10 \%$ fetal bovine serum (Biochrom, Berlin, Germany) and $1 \%$ penicillin/streptomycin (Invitrogen) in $5 \% \mathrm{CO}_{2}$ in an humidified atmosphere at $37^{\circ} \mathrm{C}$.

\section{Generation of FU-R variant AsPC-1}

An FU resistant (FU-R) variant AsPC-1 was generated by long term in vitro $\mathrm{FU}$ exposure as reported before (Ischenko et al. 2008). Stimulation by interferon gamma (IFN $\gamma$, SigmaAldrich, Taufkirchen, Germany) served as a positive control for TP expression.

\section{Irradiation of PDAC cells}

PDAC cells were irradiated with a Müller RT 250 X-ray device. Plates received either low dose IR (0.05 Gy) at a dose rate of $0.03 \mathrm{~Gy} / \mathrm{min}(225 \mathrm{kV}, 5 \mathrm{~mA})$ or intermediate dose IR $(2.0 \mathrm{~Gy})$ at a dose rate of $1 \mathrm{~Gy} / \mathrm{min}(225 \mathrm{kV}$, $15 \mathrm{~mA}$ ). A $0.35 \mathrm{~mm}$ copper-filter was used to absorb lower energy X-rays.

\section{Proliferation assay}

Cells were seeded in 96 well plates $\left(1 \times 10^{4}\right.$ cells per well $)$ $24 \mathrm{~h}$ prior to treatments. To assess cell proliferation, cells were assessed after $48 \mathrm{~h}$ using a WST-1 assay kit (Roche, Mannheim, Germany) as per manufacturer's instructions. Absorbance was measured at a wavelength of $450 \mathrm{~nm}$ on a microplate reader (Bio-Rad Laboratories, Hercule, CA, USA). $\mathrm{IC}_{50}$ was calculated according to standard guidelines.

\section{Thymidine phosphorylase gene silencing}

Total RNA isolated from AsPC-1 cells that were treated with interferon- $\gamma$ using RNeasy mini kit (Qiagen, Hilden Germany) and subjected to single step RT-PCR using SuperScript III One-Step RT-PCR System with Platinum Taq High Fidelity (Thermo Fisher, Dreieich, Germany). The primer sequences for TP si forward (TCGTGGCCGCTGTGGTGA ATGG) and TP si reverse (GCTCCCGGGCCTGCTCCT GGTT) were designed to amplify a 582 base pair PCR product specific for TP. siRNAs were generated using BLOCK-iT RNAi TOPO Transcription Kits and BLOCK-iT Dicer RNAi Kits (both Thermo Fisher) according to the manufacturer's instructions. Lipofectamine 2000 (Thermo Fisher) was used for transfecting AsPC-1 cells with the designed siRNAs. Control cells were transfected with siRNAs specific for the lacZ reporter gene which was generated in the same way using primers and templates supplied with the kit. Efficiency of TP silencing was confirmed by Western blotting. 


\section{Western blotting}

Cells were washed with ice-cold phosphate-buffered saline and resuspended in RIPA buffer supplemented with protease/phosphatase inhibitors (Roche, Mannheim, Germany) to a final concentration of about $10^{7}-10^{8}$ cells per milliliter. Equal amounts of protein were run on polyacrylamide gels, transferred to polyvinylidene difluoride membranes (Millipore, Billerica, MA, USA) and detected using an enhanced chemiluminescence system (Amersham, Braunschweig, Germany). Antibodies for TP (Cell Signaling, Frankfurt, Germany) and $\beta$-actin (Sigma-Aldrich) were used according to the manufacturers' instructions. Blots were processed with ECL plus Western blotting detection kit (Amersham) and the signal was detected using an LAS-3000 image analyzer (Fuji, Tokyo, Japan). Densitometry was performed using an AlphaImager (Alpha Innotech, San Leandro, CA, USA).

\section{Statistical analysis}

All experiments were performed three times independently. The data obtained were expressed as mean \pm standard deviation. Statistical evaluation was performed using the paired Student's $t$ test with $p<0.05$ considered to be significant.

\section{Results}

\section{FU resistance of PDAC cells}

To quantify the acquired chemoresistance of PDAC cells following prolonged $\mathrm{FU}$ exposition, cells were treated with increasing doses of $\mathrm{FU}$, and proliferation was determined. Chemoresistance was apparent at all doses applied. FU-R PDAC cells showed a 2.7-fold increase of the $\mathrm{IC}_{50}$ after $\mathrm{FU}$ exposure compared to native PDAC cells $(0.471 \mu \mathrm{M}$ versus $0.172 \mu \mathrm{M}$, Fig. 1).

\section{IR inhibits proliferation of PDAC cells}

IR inhibited the proliferation of both FU-S and FU-R PDAC cells in a dose dependent manner $(p<0.01$ for 0.05 Gy and $2.0 \mathrm{~Gy}$ versus controls, respectively). Compared to parental cells, FU-R cells were less sensitive to IR at both doses tested. Following IR with 0.05 Gy, proliferation was $80.8 \%$ of controls for FU-S cells and $93.9 \%$ of control for FURcells $(p<0.01)$. Following IR with $2.0 \mathrm{~Gy}$, proliferation was $61.2 \%$ of control for FU-S cells and $80.3 \%$ of control for FU-R cells ( $p<0.05$, Fig. 2a).

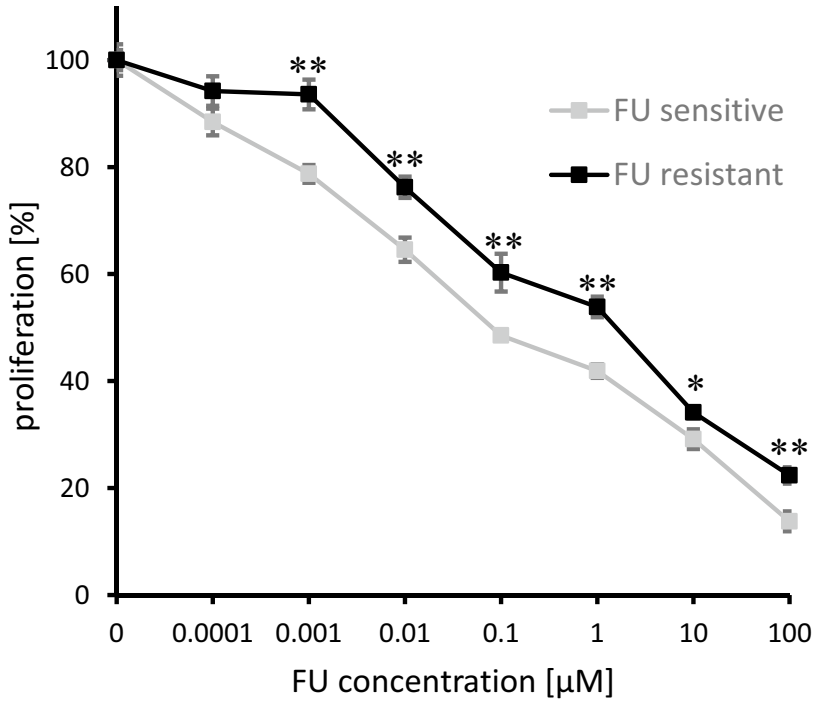

Fig. 1 Proliferation of FU sensitive (grey) and FU resistant (black) AsPC1 human PDAC cells in response to FU application. FU inhibited cell proliferation more effectively in FU sensitive than in FU resistant cells over a dose range of $0.001-100 \mu \mathrm{M}\left({ }^{*} p<0.05\right.$, $\left.{ }^{* *} p<0.01\right)$. Experiments were performed three times independently and data points are mean \pm standard deviation

\section{IR resensitizes chemoresistant PDAC cells towards FU}

Without IR, FU reduced FU sensitive cell proliferation to $55.0 \%$, and FU resistant cell proliferation to $75.8 \%$ $(p<0.01)$. After exposing cells with $0.05 \mathrm{~Gy}$ and $2.0 \mathrm{~Gy}$, respectively, we found an increased FU response in resistant cells. After IR with $0.05 \mathrm{~Gy}$, proliferation was reduced to $61.8 \%$ of control for FU-S cells and $44.9 \%$ of control for FU-R cells $(p<0.01)$. After IR with $2.0 \mathrm{~Gy}$, proliferation was reduced to $54.7 \%$ of control for FU-S cells and $41.9 \%$ of control for FU-R cells ( $p<0.01$, Fig. $2 b$ ).

\section{IR upregulates TP protein expression in PDAC cells}

Western blotting was used after exposing FU-R PDAC cells to IR. IFN $\gamma$ was used as positive control. Following IR with $0.05 \mathrm{~Gy}$ and $2.0 \mathrm{~Gy}$, respectively, a time dependent upregulation of TP protein expression was seen (Fig. 3a).

\section{PDAC cell resensitization by IR is dependent on TP}

To determine the specificity of the resensitization effect, we used siRNA knockdown of TP. After TP silencing, FU-R cells did not show a decrease in proliferation after FU exposure preceded by IR with 0.05 Gy and $2.0 \mathrm{~Gy}$. Proliferation of FU-R cells after FU exposure was 56.2\% of control without IR, $59.6 \%$ of control for 0.05 Gy and $48.6 \%$ of control for $2.0 \mathrm{~Gy}$ IR. In contrast, proliferation of 


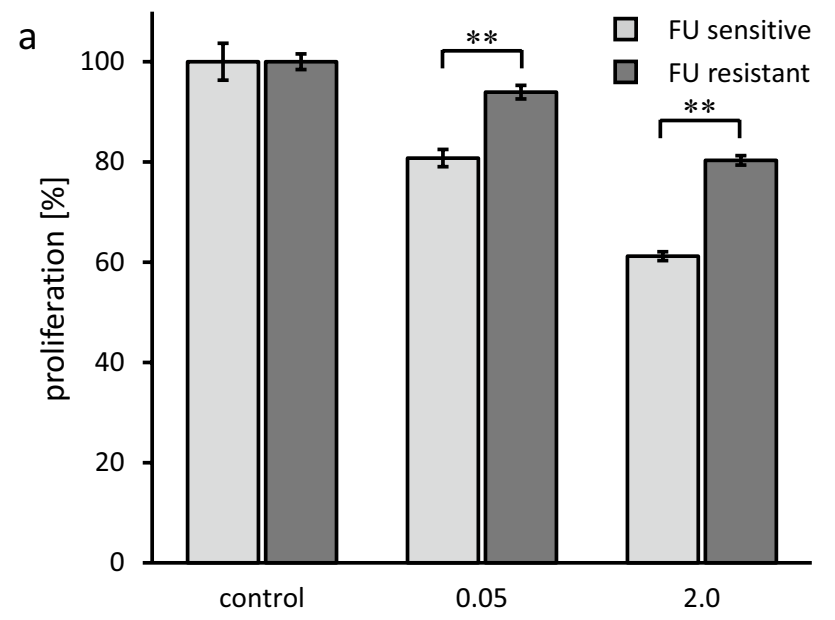

IR dose [Gy]

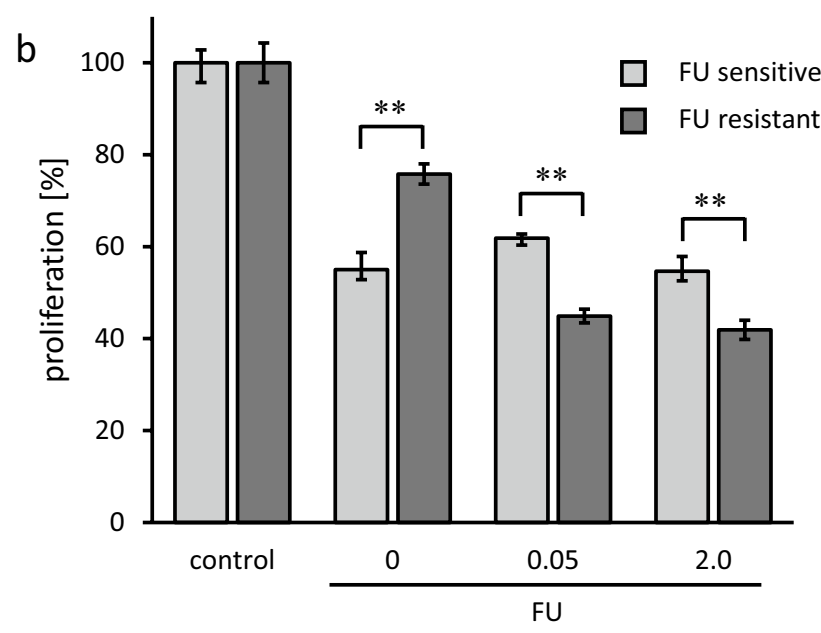

IR dose $[\mathrm{Gy}]$

Fig. 2 Proliferation of FU sensitive (light grey bars) and FU resistant (dark grey bars) AsPC1 human PDAC cells. a Proliferation in response to low dose $(0.05 \mathrm{~Gy})$ and intermediate dose (2.0 Gy) IR. FU resistant cells showed concomitant IR resistance towards both doses $(* * p<0.01)$. b Proliferation in response to FU was less inhibited in FU resistant cells not previously exposed to IR $(* * p<0.01)$. Following low dose ( 0.05 Gy) or intermediate dose (2 Gy) IR, FU inhibited proliferation more effectively in FU resistant cells than in FU sensitive cells $(* * p<0.01)$. Experiments were performed three times independently and data points are mean \pm standard deviation

FU-R cells was affected by IR in addition to FU exposure in the control group where proliferation of FU-R cells after FU exposure was $60.2 \%$ of control without IR $(p<0.01)$, $36.3 \%$ of control for $0.05 \mathrm{~Gy}(p<0.01)$, and $27.6 \%$ of control for $2.0 \mathrm{~Gy}(p<0.01)$. In both groups, FU-S cells did show a decrease in proliferation after FU exposure with and without additional IR which was statistically significant ( $p<0.01$, Fig. 3b).

\section{Discussion}

Chemoresistance is a major obstacle to systemic therapy of PDAC with overall response rates to modern FU based regimens found to be about 35\% (Adamska et al. 2018; Tong et al. 2018). In this study, we used an FU-S human PDAC cell line and its FU-R variant. Cells of both lines were irradiated with 0.05 and 2.0 Gy prior to FU exposition. Following IR, we noted an increase in 5-FU sensitivity of the FU-R PDAC cells. We could further show that IR upregulates TP which is a key enzyme of the FU metabolism necessary for its biological activation. When TP expression was blocked by siRNA, the resensitization effect of IR on FU-R PDAC cells was mitigated. We thus assumed that this effect of IR on PDAC cells was specifically mediated by TP.

Different tumor-related chemotherapy resistance mechanisms lead to decreased efficacy of cytotoxic drugs. As FU targets intracellular enzymes, its efficiency depends on transport systems including human equilibrative nucleoside transporters (hENTs) and concentrative nucleoside transporters (hCNTs). High expression of hENT1 mRNA leads to FU resistance in PDAC, and inhibition of hENT1 can increase the intracellular FU concentration in human PDAC cells and so enhance cytotoxicity (Wang et al. 2014). Other transport proteins involved in FU uptake include human organic anion transporter 2 (hOat2, SLC22A7). Its expression correlates with chemoresistance in PDAC cells, whereas expression of multidrug-resistance protein 5 (MRP5, ABCC5) is associated with 5-FU sensitivity (Wang et al. 2014). Furthermore, FU resistance is conferred by altered expression of genes involved in cell cycle regulation, proliferation, repair and apoptosis, as DNA and RNA damage caused by FU leads to the activation of DNA repair systems or apoptosis. Several cell survival pathways are involved in FU resistance, including the EGFR/MAPK/ERK, Akt/mTOR, Jak/STAT3, PI3K/ $\mathrm{NFKB}$ and $\mathrm{WNT} / \mathrm{GSK} 3 \mathrm{~b} / \beta$-catenin signaling cascades (Wang et al. 2014). Furthermore, cancer stem cell features and distinct micro RNA expression patterns contribute to chemotherapy resistance in PDAC (Niess et al. 2015; Zhao et al. 2015).

Apart from the more universal resistance mechanisms, specific effects related to intracellular FU metabolism have been found. Two pathways have been identified to synthesize FdUMP from FU: (1) orotate phosphoribosyltransferase converts FU to 5-fluorouridine monophosphate (FUMP) which is converted to FdUMP in several further steps, and (2) TP converts FU to 5-fluoro-deoxyuridine (FdU), which is converted to fdUMP by thymidine kinase (TK). FdUMP itself inhibits thymidine synthase (TS) which leads to the disruption of DNA de novo synthesis. 
Fig. 3 IR upregulates TP and PDAC cell resensitization is dependent on TP. a TP protein expression in FU resistant AsPC1 cells following low dose $(0.05 \mathrm{~Gy})$ and intermediate dose (2.0 Gy) IR. Both low dose and intermediate dose IR upregulated TP expression in FU resistant cells. b Proliferation of FU sensitive (light grey bars) and FU resistant (dark grey bars) AsPC1 human PDAC cells. Anti TP siRNA was used to block TP upregulation, and LacZ siRNA served as control. In control cells, following IR at $0.05 \mathrm{~Gy}$ as well as $2.0 \mathrm{~Gy}$, proliferation was inhibited more effectively in FU resistant cells than in FU sensitive cells $(* * p<0.01)$ when challenged with FU. When TP expression was blocked, this effect was abolished. Experiments were performed three times independently and data points are mean \pm standard deviation a

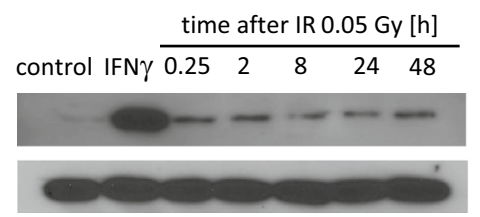

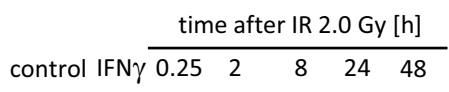
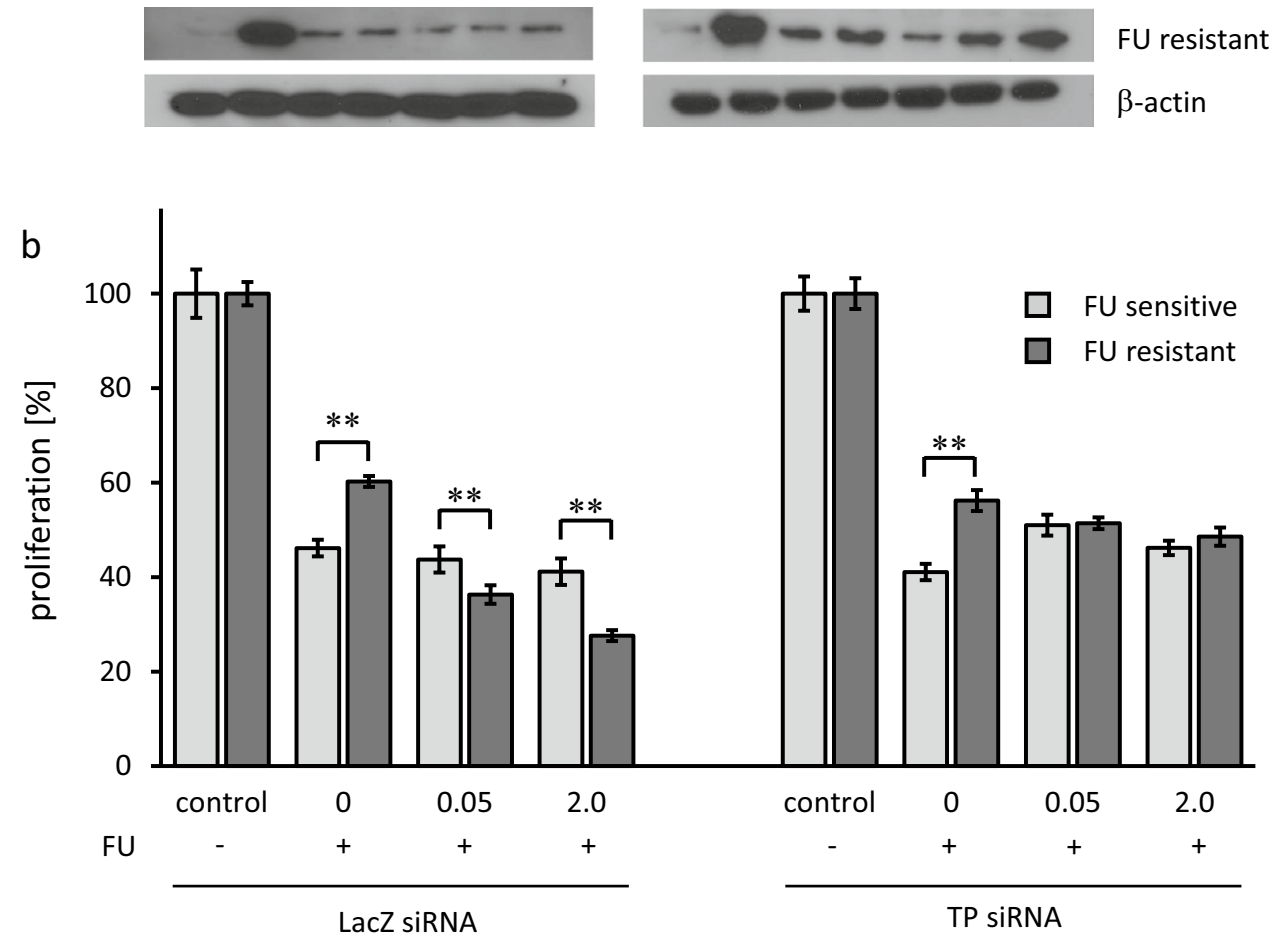

IR dose [Gy]

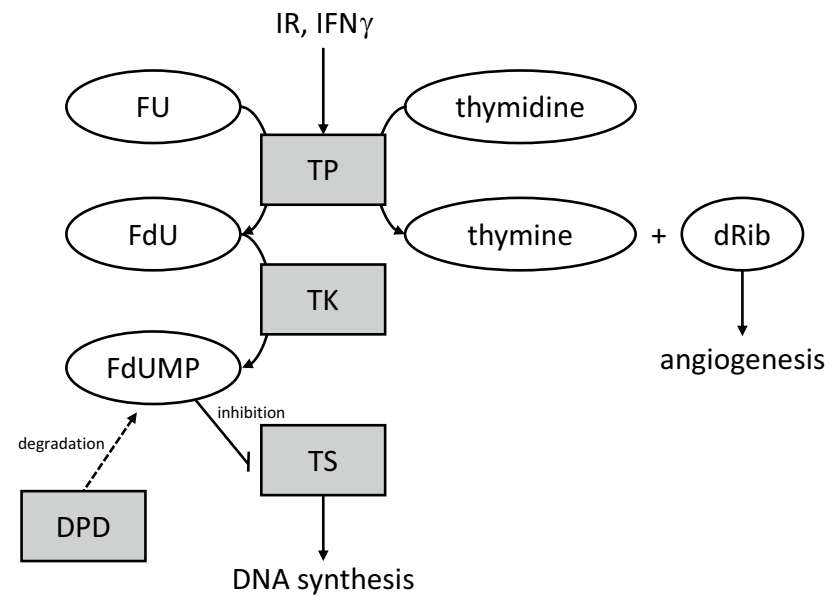

Fig. 4 Metabolism of 5-fluorouracil and thymidine phosphorylase

FdUMP then is inactivated by dihydropyrimidine dehydrogenase (DPD) (Wei et al. 1996). Thus, FU resistance can result from an imbalance of FdUMP synthesis and its degradation as well as an overexpression of TS (Fig. 4).

In our experiments, we used a FU-R variant of AsPC-1 PDAC cells that was generated and characterized earlier by our group (Ischenko et al. 2008). Our earlier experiments showed that FU resistance in this system depends at least in part on upregulation of TS mRNA and protein expression that was abolished indirectly by $s r c$ inhibition (Ischenko et al. 2008). Interestingly, there was no difference in DPD expression between FU-S and FU-R cells, suggesting that FU degradation by DPD is not a relevant resistance mechanism at least in the cell lines examined (Ischenko et al. 2008). Based on these data, we then asked whether a modification of TP expression by IR would also alter FU resistance in PDAC cells.

Chemotherapy resistance and IR resistance share phenotypic characteristics, such as the activation of the Jak/STAT3 signaling cascade, loss of Smad4 expression and the expression of multidrug-resistance proteins (Chen et al. 2014; Hou et al. 2014; Oike and Ohno 2020; Wang et al. 2018). In this context, it is not surprising that in our experiments FU-R PDAC cells were radioresistant as well. In line with our findings, clinical and translational studies have proven simultaneous IR and chemotherapy resistance in PDAC and other solid tumors (Orth et al. 2019). FU itself is well established in clinical regimens of combined radiochemotherapy, exploiting its property as a radiosensitizing agent (Buckley et al. 2020).

In contrast, the reverse concept of IR acting as a chemosensitizer is less well defined. Our experiments showed that FU treatment of PDAC cells following different doses of IR results in a significant reduction of tumor 
cell proliferation in chemoresistant cells. It is remarkable that following IR, FU-R tumor cells responded even better to chemotherapy than the parental FU-S cells. This in turn may result in a higher degree of FU conversion into FdUMP, causing more pronounced cytotoxic effects (Lindskog et al. 2014; Longley et al. 2003). When TP expression was blocked by siRNA, the sensitivity of FU-resistant cells towards IR was eliminated. In line with our results, IR has been shown before to upregulate TP, but the underlying mechanism is not fully understood yet (Derwinger et al. 2013).

Besides examining an intermediate IR dose of $2 \mathrm{~Gy}$, we were interested in the effects of a low dose of $0.05 \mathrm{~Gy}$ on FU resistance reversal. Low dose or radioadaptive dosing has been shown to have protective effects on tumor surrounding tissue when afterwards challenged with higher IR doses and increases radiosensitivity of tumor cells (Hou et al. 2015; Schwarz et al. 2008). Since proliferative responses of PDAC cells towards FU were similar after IR at both doses examined, direct IR effects may be less important in our setting than chemosensitizing effects by IR. In fact, radioadaptive IR dosing alters protein expression in non-tumor as well as in tumor cells (Coleman et al. 2005; Hou et al. 2015). Furthermore, IR has been shown to induce inflammation and matrix remodeling, thereby also increasing diverse biomarkers and cytokines (Di Maggio et al. 2015). Thus, it is plausible that IR induces an increase in TP as part of the inflammatory process (Derwinger et al. 2013). Conversely, it has been demonstrated that low dose IR exerts anti-inflammatory responses (Deloch et al. 2018; Schroder et al. 2018). Since inflammatory signaling cascades crosstalk with tumor promoting signaling pathways in PDAC (Pozios et al. 2020; Zhang et al. 2013), attenuating inflammation by low dose IR may have beneficial effects in chemoresistant cells.

Since we did our experiments in vitro in this pilot study, we cannot rule out angiogenic effects of TP confounding the restoration of chemosensitivity in PDAC by IR. However, earlier data of our group indicate that dRib generated from thymidine breakdown by TP exerts a strong angiogenic effect on endothelial cells (Seeliger et al. 2004). Thus, it remains to be established in which way IR interacts with angiogenesis in vivo. Further, effects of the expression of $\mathrm{TP}$ in stromal cells in the tumor interstitium remain to be established, as the microenvironment of the tumor can also be involved in the emergence of chemoresistance (Wang et al. 2014).

In conclusion, we were able to show that IR can revert chemoresistance towards FU in PDAC by a specific TPmediated mechanism. Further experiments should address effects of IR towards the tumor microenvironment and tumor angiogenesis. In perspective, TP directed therapeutic regimens including low dose IR may be beneficial in the clinical treatment of PDAC.
Acknowledgements The authors thank Ulrike Kulka and Ying Xin for excellent technical assistance and Marisa T. Martin for proofreading the manuscript. HS conducted part of the study design, data collection and analysis while on a scientific rotation position funded by the Deutsche Forschungsgemeinschaft (DFG, KFO128).

Author contributions HS, CJB and SBN designed the study. IP, SBN and HS performed research. LDL, IP, VL, SBN, DB, CK and HS analyzed data. LDL, VL, SBN, KB, MEK and HS wrote the paper.

Funding Open Access funding enabled and organized by Projekt DEAL. HS conducted part of the study design, data collection and analysis while on a scientific rotation position funded by the Deutsche Forschungsgemeinschaft (DFG, KFO128).

Availability of data and material Raw data and materials are available on request.

Code availability Not applicable.

\section{Declarations}

Conflict of interest All authors declare that there are no conflicts of interest/competing interests.

Ethics approval Not applicable.

Consent to participate Not applicable.

Consent for publication Not applicable.

Open Access This article is licensed under a Creative Commons Attribution 4.0 International License, which permits use, sharing, adaptation, distribution and reproduction in any medium or format, as long as you give appropriate credit to the original author(s) and the source, provide a link to the Creative Commons licence, and indicate if changes were made. The images or other third party material in this article are included in the article's Creative Commons licence, unless indicated otherwise in a credit line to the material. If material is not included in the article's Creative Commons licence and your intended use is not permitted by statutory regulation or exceeds the permitted use, you will need to obtain permission directly from the copyright holder. To view a copy of this licence, visit http://creativecommons.org/licenses/by/4.0/.

\section{References}

Adamska A, Elaskalani O, Emmanouilidi A, Kim M, Abdol Razak NB, Metharom P, Falasca M (2018) Molecular and cellular mechanisms of chemoresistance in pancreatic cancer. Adv Biol Regul 68:77-87. https://doi.org/10.1016/j.jbior.2017.11.007

Bronckaers A, Gago F, Balzarini J, Liekens S (2009) The dual role of thymidine phosphorylase in cancer development and chemotherapy. Med Res Rev 29(6):903-953. https://doi.org/10.1002/ med.20159

Buckley AM, Lynam-Lennon N, O'Neill H, O'Sullivan J (2020) Targeting hallmarks of cancer to enhance radiosensitivity in gastrointestinal cancers. Nat Rev Gastroenterol Hepatol 17(5):298-313. https://doi.org/10.1038/s41575-019-0247-2

Chen YW, Hsiao PJ, Weng CC, Kuo KK, Kuo TL, Wu DC, Hung WC, Cheng KH (2014) SMAD4 loss triggers the phenotypic changes 
of pancreatic ductal adenocarcinoma cells. BMC Cancer 14:181. https://doi.org/10.1186/1471-2407-14-181

Coleman MA, Yin E, Peterson LE, Nelson D, Sorensen K, Tucker JD, Wyrobek AJ (2005) Low-dose irradiation alters the transcript profiles of human lymphoblastoid cells including genes associated with cytogenetic radioadaptive response. Radiat Res 164(4 Pt 1):369-382. https://doi.org/10.1667/rr3356.1

Conroy T, Desseigne F, Ychou M, Bouche O, Guimbaud R, Becouarn Y, Adenis A, Raoul JL, Gourgou-Bourgade S, de la Fouchardiere C, Bennouna J, Bachet JB, Khemissa-Akouz F, Pere-Verge D, Delbaldo C, Assenat E, Chauffert B, Michel P, Montoto-Grillot C, Ducreux M, Groupe Tumeurs Digestives of U, Intergroup P (2011) FOLFIRINOX versus gemcitabine for metastatic pancreatic cancer. N Engl J Med 364(19):1817-1825. https://doi.org/10. 1056/NEJMoa1011923

Conroy T, Hammel P, Hebbar M, Ben Abdelghani M, Wei AC, Raoul JL, Chone L, Francois E, Artru P, Biagi JJ, Lecomte T, Assenat E, Faroux R, Ychou M, Volet J, Sauvanet A, Breysacher G, Di Fiore F, Cripps C, Kavan P, Texereau P, Bouhier-Leporrier K, Khemissa-Akouz F, Legoux JL, Juzyna B, Gourgou S, O'Callaghan CJ, Jouffroy-Zeller C, Rat P, Malka D, Castan F, Bachet JB, Canadian Cancer Trials G, the Unicancer GIPG (2018) FOLFIRINOX or gemcitabine as adjuvant therapy for pancreatic cancer. N Engl J Med 379(25):2395-2406. https:// doi.org/10.1056/NEJMoa1809775

Deloch L, Derer A, Hueber AJ, Herrmann M, Schett GA, Wolfelschneider J, Hahn J, Ruhle PF, Stillkrieg W, Fuchs J, Fietkau R, Frey B, Gaipl US (2018) Low-dose radiotherapy ameliorates advanced arthritis in hTNF-alpha tg mice by particularly positively impacting on bone metabolism. Front Immunol 9:1834. https://doi.org/10.3389/fimmu.2018.01834

Derwinger K, Lindskog EB, Palmqvist E, Wettergren Y (2013) Changes in thymidine phosphorylase gene expression related to treatment of rectal cancer. Anticancer Res 33(6):2447-2451

Di Maggio FM, Minafra L, Forte GI, Cammarata FP, Lio D, Messa C, Gilardi MC, Bravata V (2015) Portrait of inflammatory response to ionizing radiation treatment. J Inflamm (Lond) 12:14. https://doi.org/10.1186/s12950-015-0058-3

Dikici S, Aldemir Dikici B, Bhaloo SI, Balcells M, Edelman ER, MacNeil S, Reilly GC, Sherborne C, Claeyssens F (2019) Assessment of the angiogenic potential of 2-deoxy-d-ribose using a novel in vitro 3D Dynamic model in comparison with established in vitro assays. Front Bioeng Biotechnol 7:451. https://doi.org/10.3389/fbioe.2019.00451

Hasegawa K, Okamoto H, Kawamura K, Kato R, Kobayashi Y, Sekiya T, Udagawa Y (2012) The effect of chemotherapy or radiotherapy on thymidine phosphorylase and dihydropyrimidine dehydrogenase expression in cancer of the uterine cervix. Eur J Obstet Gynecol Reprod Biol 163(1):67-70. https://doi. org/10.1016/j.ejogrb.2012.03.014

Hou DL, Chen L, Liu B, Song LN, Fang T (2014) Identification of common gene networks responsive to radiotherapy in human cancer cells. Cancer Gene Ther 21(12):542-548. https://doi. org/10.1038/cgt.2014.62

Hou J, Wang F, Kong P, Yu PK, Wang H, Han W (2015) Gene profiling characteristics of radioadaptive response in AG01522 normal human fibroblasts. PLOS ONE 10(4):e0123316. https://doi. org/10.1371/journal.pone.0123316

Ischenko I, Camaj P, Seeliger H, Kleespies A, Guba M, De Toni EN, Schwarz B, Graeb C, Eichhorn ME, Jauch KW, Bruns CJ (2008) Inhibition of Src tyrosine kinase reverts chemoresistance toward 5-fluorouracil in human pancreatic carcinoma cells: an involvement of epidermal growth factor receptor signaling. Oncogene 27(57):7212-7222. https://doi.org/10.1038/onc.2008.326

Lindskog EB, Derwinger K, Gustavsson B, Falk P, Wettergren Y (2014) Thymidine phosphorylase expression is associated with time to progression in patients with metastatic colorectal cancer. BMC Clin Pathol 14:25. https://doi.org/10.1186/ 1472-6890-14-25

Liu X, Chen H, Hou Y, Ma X, Ye M, Huang R, Hu B, Cao H, Xu L, Liu M, Li L, Gao J, Bai Y (2019) Adaptive EGF expression sensitizes pancreatic cancer cells to ionizing radiation through activation of the cyclin D1/P53/PARP pathway. Int J Oncol 54(4):1466-1480. https://doi.org/10.3892/ijo.2019.4719

Longley DB, Harkin DP, Johnston PG (2003) 5-fluorouracil: mechanisms of action and clinical strategies. Nat Rev Cancer 3(5):330 338. https://doi.org/10.1038/nrc1074

Niess H, Camaj P, Renner A, Ischenko I, Zhao Y, Krebs S, Mysliwietz J, Jackel C, Nelson PJ, Blum H, Jauch KW, Ellwart JW, Bruns CJ (2015) Side population cells of pancreatic cancer show characteristics of cancer stem cells responsible for resistance and metastasis. Target Oncol 10(2):215-227. https://doi.org/10.1007/ s11523-014-0323-z

Oike T, Ohno T (2020) Molecular mechanisms underlying radioresistance: data compiled from isogenic cell experiments. Ann Transl Med 8(6):273. https://doi.org/10.21037/atm.2020.02.90

Orth M, Metzger P, Gerum S, Mayerle J, Schneider G, Belka C, Schnurr M, Lauber K (2019) Pancreatic ductal adenocarcinoma: biological hallmarks, current status, and future perspectives of combined modality treatment approaches. Radiat Oncol 14(1):141. https:// doi.org/10.1186/s13014-019-1345-6

Pozios I, Seel NN, Hering NA, Hartmann L, Liu V, Camaj P, Muller MH, Lee LD, Bruns CJ, Kreis ME, Seeliger H (2020) Raloxifene inhibits pancreatic adenocarcinoma growth by interfering with ERbeta and IL-6/gp130/STAT3 signaling. Cell Oncol (dordr). https://doi.org/10.1007/s13402-020-00559-9

Schroder S, Kriesen S, Paape D, Hildebrandt G, Manda K (2018) Modulation of inflammatory reactions by low-dose ionizing radiation: cytokine release of murine endothelial cells is dependent on culture conditions. J Immunol Res 2018:2856518. https://doi.org/10. $1155 / 2018 / 2856518$

Schuller J, Cassidy J, Dumont E, Roos B, Durston S, Banken L, Utoh M, Mori K, Weidekamm E, Reigner B (2000) Preferential activation of capecitabine in tumor following oral administration to colorectal cancer patients. Cancer Chemother Pharmacol 45(4):291-297. https://doi.org/10.1007/s002800050043

Schwarz SB, Schaffer PM, Kulka U, Ertl-Wagner B, Hell R, Schaffer M (2008) The effect of radio-adaptive doses on HT29 and GM637 cells. Radiat Oncol 3:12. https://doi.org/10.1186/1748-717X-3-12

Seeliger H, Guba M, Koehl GE, Doenecke A, Steinbauer M, Bruns CJ, Wagner C, Frank E, Jauch KW, Geissler EK (2004) Blockage of 2-deoxy-D-ribose-induced angiogenesis with rapamycin counteracts a thymidine phosphorylase-based escape mechanism available for colon cancer under 5-fluorouracil therapy. Clin Cancer Res 10(5):1843-1852. https://doi.org/10.1158/1078-0432.ccr-1176-3

Siegel RL, Miller KD, Jemal A (2020) Cancer statistics. CA Cancer J Clin 70(1):7-30. https://doi.org/10.3322/caac.21590

Toi M, Bando H, Horiguchi S, Takada M, Kataoka A, Ueno T, Saji S, Muta M, Funata N, Ohno S (2004) Modulation of thymidine phosphorylase by neoadjuvant chemotherapy in primary breast cancer. Br J Cancer 90(12):2338-2343. https://doi.org/10.1038/ sj.bjc. 6601845

Tong H, Fan Z, Liu B, Lu T (2018) The benefits of modified FOLFIRINOX for advanced pancreatic cancer and its induced adverse events: a systematic review and meta-analysis. Sci Rep 8(1):8666. https://doi.org/10.1038/s41598-018-26811-9

van Roessel S, van Veldhuisen E, Klompmaker S, Janssen QP, Abu Hilal M, Alseidi A, Balduzzi A, Balzano G, Bassi C, Berrevoet F, Bonds M, Busch OR, Butturini G, Del Chiaro M, Conlon KC, Falconi M, Frigerio I, Fusai GK, Gagniere J, Griffin O, Hackert T, Halimi A, Klaiber U, Labori KJ, Malleo G, Marino MV, Mortensen MB, Nikov A, Lesurtel M, Keck T, Kleeff J, Pande R, 
Pfeiffer P, Pietrasz D, Roberts KJ, Sa Cunha A, Salvia R, Strobel O, Tarvainen T, Bossuyt PM, van Laarhoven HWM, Wilmink JW, Groot Koerkamp B, Besselink MG, European-African HepatoPancreato-Biliary A (2020) Evaluation of adjuvant chemotherapy in patients with resected pancreatic cancer after neoadjuvant FOLFIRINOX treatment. JAMA Oncol. https://doi.org/10.1001/jamao ncol.2020.3537

Wang WB, Yang Y, Zhao YP, Zhang TP, Liao Q, Shu H (2014) Recent studies of 5-fluorouracil resistance in pancreatic cancer. World $\mathrm{J}$ Gastroenterol 20(42):15682-15690. https://doi.org/10.3748/wjg. v20.i42.15682

Wang F, Xia X, Yang C, Shen J, Mai J, Kim HC, Kirui D, Kang Y, Fleming JB, Koay EJ, Mitra S, Ferrari M, Shen H (2018) SMAD4 gene mutation renders pancreatic cancer resistance to radiotherapy through promotion of autophagy. Clin Cancer Res 24(13):31763185. https://doi.org/10.1158/1078-0432.CCR-17-3435

Wei X, McLeod HL, McMurrough J, Gonzalez FJ, Fernandez-Salguero $P$ (1996) Molecular basis of the human dihydropyrimidine dehydrogenase deficiency and 5-fluorouracil toxicity. J Clin Invest 98(3):610-615. https://doi.org/10.1172/JCI118830
Zhang Y, Yan W, Collins MA, Bednar F, Rakshit S, Zetter BR, Stanger BZ, Chung I, Rhim AD, di Magliano MP (2013) Interleukin-6 is required for pancreatic cancer progression by promoting MAPK signaling activation and oxidative stress resistance. Cancer Res 73(20):6359-6374. https://doi.org/10.1158/0008-5472. CAN-13-1558-T

Zhao Y, Zhao L, Ischenko I, Bao Q, Schwarz B, Niess H, Wang Y, Renner A, Mysliwietz J, Jauch KW, Nelson PJ, Ellwart JW, Bruns CJ, Camaj P (2015) Antisense inhibition of microRNA-21 and microRNA-221 in tumor-initiating stem-like cells modulates tumorigenesis, metastasis, and chemotherapy resistance in pancreatic cancer. Target Oncol 10(4):535-548. https://doi.org/10. 1007/s11523-015-0360-2

Publisher's Note Springer Nature remains neutral with regard to jurisdictional claims in published maps and institutional affiliations. 